ISSN: 2162-3104 Print/ ISSN: 2166-3750 Online Volume 7, Issue 3 (2017), pp. 522-541 (C) Journal of International Students

http://jistudents.org/ doi:10.5281/zenodo.570013

\title{
The Effects of a Roommate-Pairing Program on International Student Satisfaction and Academic Success
}

\author{
Steven Tolman \\ Georgia Southern University, USA
}

\begin{abstract}
While great attention has been given to the growth of international students at U.S. institutions, there is a gap in the literature examining support for this student population within residence halls. To address the gap, this quantitative study evaluated an international roommate-pairing program (IRP) by comparing the residential experience of IRP participants with a control group. The results showed the roommate-pairing program had a positive impact on the residential experience of international students. These findings suggest physical environment and structured support are critical factors in the satisfaction and success of international students. This research can inform the practice of Residence Life professionals and aid in the establishment of effective support programs.
\end{abstract}

Keywords: international students, residence halls, Residence Life, roommate-pairing, satisfaction

International students are one of the fastest growing populations in higher education. Their enrollment increased by ten percent at U.S. institutions between the 2013 and 2014 academic years (IIE, 2015). Currently, there are approximately 975,000 international students studying in the U.S., which makes up five percent of the total student enrollment at universities. The benefits of this increased enrollment are twofold. Firstly, it diversifies the academic community of higher education, thus enabling students to learn from each other's differences (Wilhelm, 2011). Many colleges are striving for an environment that promotes a vision of global education and the foundation of cultural tolerance. The addition and integration of international students plays a significant role in universities achieving this goal. Our ability to create this highly desired global environment would be 
greatly diminished if U.S. institutions become unable to recruit and retain international students.

Secondly, increased international enrollment is a matter of dollars and cents. Not only have institutions come to rely on the financial incentives of international students, but the U.S. economy has benefited as well. It is estimated that international students generate close to $\$ 30.8$ billion annually to the U.S. economy (IIE, 2015). Subsequently, there is financial incentive to U.S. universities (and their cities) to enroll international students, as they are a consistent and substantial stream of financial revenue. According to Aw (2012), "The U.S. faces serious global competition and may be in real danger of losing its dominance as the destination of choice for international students” (p. 10). Removing this flow of income would be detrimental to higher education within the U.S. and could have a crippling effect on struggling institutions' financial stability.

Recognizing their contribution to the university, satisfaction and success of this student population warrants attention. Universities cannot take for granted international students will always choose U.S. institutions, as there has become global competition for this student population (Becker \& Kolster, 2012; Hegarty, 2014). Throughout the world, universities are developing programs to attract international students to their campuses. If U.S. institutions are not creating an exceptional academic experience, these students may choose other countries for their higher education needs. While support programs have been the subject of extensive research, few studies examine targeted support for international students within the residence halls. To address the literature gap, this quantitative study explored the residential experience of international students and the impact of participation in a roommate-pairing program. The following research questions were addressed: 1) Does participation in an international roommate-pairing program have a positive impact on the satisfaction of international students? 2) Does participation have a positive impact on their academic success?

\section{LITERATURE REVIEW}

\section{Supporting Academic Success \& Persistence}

The academic success of international students hinges on support inside and out of the classroom (Andrade, 2006). Factors impacting their success include communication and English skills (Andrade, 2006; Mamiseishvili, 2012; Woodrow, 2006), support from faculty (Andrade, 2006; McLachlan \& Justice, 2009), social networks (Andrade, 2005; Gomez, Urzua, \& Glass, 2014), participation in support programs (Abe, Talbot, and Geelhoed, 1998; Geelhoed, Abe, and Talbot, 2003; Kovtun, 2011; Menzies, Brown, \& Zutshi, 2015; Quintrell and Westwood, 1994), 
and campus and residential experiences (Chong \& Razek, 2014; Tas, 2013; Terkla, Roscoe, \& Etish-Andrews, 2005). Recognizing the impact these factors play in the success of international students, administrators and educators can develop best practices to address them and in turn better help international students achieve academic success at the university.

Directly connected to academic achievement is persistence, which a common theme in the literature and recent studies (Andrade, 2005; Kwai, 2009; Mamiseishvili, 2012). Particularly interesting is the longitudinal study of 200 mixed class-year international students that found GPA, degree plan, and academic integration were positively correlated with persistence while English remediation and social integration were negatively correlated (Mamiseishvili, 2012). These findings reinforce that experiences outside of the classroom impact international students' academic success. International students feel pressure to be successful academically (Hegarty, 2014; McLachlan \& Justice, 2009). In order to do so, many feel the need to focus solely on their academics and forgo a social life (Andrade, 2006). This is especially concerning, as social integration is a major factor in the satisfaction and academic success of international students.

\section{The Need for Social Networks}

The establishment of social networks for international students is critical in their adjustment and acclimation (Andrade, 2005; Gomez et al., 2014; Rajapaksa \& Dundes, 2002; Ramsay, Jones, \& Barker, 2007). Understandably, international students typically do not have a social network in place when coming to an American university. Subsequently, if they are unable to establish friendships, students may not leave their room except to attend class, which can lead to a feeling of isolation. This isolation is a difficult adjustment for many international students (McLachlan \& Justice, 2009; Sawir, Marginson, Deumert, Nyland, \& Ramia, 2008; Tompson \& Tompson, 1996). Therefore, it is not surprising that international students are more likely than their domestic counterparts to feel lonely and homesick (Rajapaksa \& Dundes, 2002). Clearly, there is a benefit and need for establishing social networks. This reinforces the need to examine support programs and develop mechanisms to increase opportunities for social interaction.

\section{Residential Experience}

The residential experience of international students can impact their academic success and satisfaction at the university (Chong \& Razek, 2014; Tas, 2013; Terkla et al., 2005). The department responsible for managing residence halls and residential students at U.S. institutions is typically referred to as Residence Life. Recognizing the important role Residence Life has in shaping the experience of international students, greater focus 
should be placed on examining the residential experience and finding ways to strengthen it. At the heart of this residential experience are social interactions and the feeling of belonging to the campus community. One of the primary expectations and desires of international students is to interact with domestic students. Paradoxically, international students are less likely to develop relationships with domestic students and tend to "stick together" (Dodge, 1990; McFaul, 2016). Subsequently, this suggests the need for Residence Life to intervene to help facilitate this experience. To this end, residence halls can serve as a vehicle for intentional interaction between domestic and international students.

While there are benefits to pairing international students with domestic roommates, this also creates a new set of challenges for international students. In addition to the typical adjustments that need to be made when living with any roommate, the added cultural differences between international and domestic roommates can be particularly challenging (Antonio \& Ofori-Dwumfuo, 2015). As a result, living with a domestic student can also be a source of stress for international students (Terkla et al., 2005). Recognizing this challenge, it is important for Residence Life to consider proactive approaches to mitigate these concerns. Approaches could include intentional roommate-pairing programs that foster communication between roommates early on in an effort to build healthy relationships and develop tolerance.

Acknowledging this, there is a need to empirically examine the formation and development of relationships between roommates. Saidla and Parodi (1991) explored roommate relationships in a mixed methods study of 30 roommate pairings. They found no differences in rapport between international/domestic roommates compared to domestic/domestic roommates. Moreover, living with an international roommate had greater impact on the cognitive development of domestic students. This reinforces the notion that globalizing the university community through increasing international student enrollment can further develop domestic students. The study was replicated and again found no differences in rapport between American/domestic and domestic/domestic roommate pairings (Saidla \& Grant, 1993). The literature would be strengthened by further studies examining this.

In addition to roommates, another inextricable component of the residential experience is the need to navigate food options. This can be a challenge, as institutions often fail to accommodate dining preferences of international students despite their greater dietary needs compared to domestic students. International students report challenges with American food and typical college food (McLachlan \& Justice, 2009; Terkla et al., 2005). In a quantitative study of 1,161 domestic and 335 international students, international students had lower food satisfaction level (3.08 out of 
5) compared to domestic students (3.44 out of 5) (Grebinnikov \& Skaines, 2007). Similarly, a quantitative study found $90 \%$ of international students experienced problems or dissatisfaction with food on campus (Al-Mubarak, 2000). Given that many campuses require residential students to have at least a partial meal plan, greater consideration should be given to the dietary needs and preferences of international students.

\section{Peer-Pairing Support Programs}

Acknowledging that peers are central to student persistence (Astin, 1975), peer-pairing programs offer a promising mechanism to support international students and their successful transition to the university. Peerpairing programs establish a mentor role between international and domestic students (Quintrell \& Westwood, 1994). Host students are typically trained on the needs of international students and provided resources to support them. Furnham and Bochner (1982) assert that "If sojourners are carefully introduced into a new society by close, sympathetic host culture and friends, the evidence indicates that they may encounter fewer problems than if they are left to fend for themselves” (p.71). These peer-pairing programs can benefit both the international and domestic students participating. The international student receives a layer of support (from a peer), has an established social network immediately, and receives the desired interaction with a domestic student. This interaction with domestic students is crucial, as it has been found it leads to international students being more satisfied, socially connected, and less homesick (Hendrickson, Rosen, \& Aune, 2010). Conversely, the domestic student has the opportunity to interact with someone from another country, develop a global perspective, and many will subsequently consider international travel.

The literature supports the positive impact of peer-pairing programs (Abe et al., 1998; Geelhoed et al., 2003; Menzies et al., 2015; Quintrell and Westwood, 1994; Ragavan, 2014). For example, the study by Quintrell and Westwood (1994) compared the experiences of 41 peer-paired international students with their non-participatory counterparts. It was found that structured interaction between international and domestic students enhanced the experience of international students. Furthermore, international students in this peer-pairing program were more likely to have positive views of their experience at the university, utilize campus services, and have gains in language fluency. Similarly, a quantitative study examined the impact of an international peer-pairing program that was a collaboration between Residence Life and International Student Services (Abe et al., 1998). This study compared experiences of 28 international student participants paired with a domestic student (not as roommates) with the experiences of 32 nonparticipants. Students who participated in the peer-pairing program were more successful in their social adjustment than their peers. As to be 
expected, it also found that adjustment was higher for participants who previously lived in the United States.

\section{THEORETICAL FRAMEWORK}

Schlossberg's Transition Theory (Schlossberg, Waters \& Goodman, 1995) is the primary theoretical framework for this study. This theory examines different forms of transitions, the transition process, and factors influencing the likelihood of successfully completing a transition. First-year international students are an exemplar of individuals in transition. They are navigating higher education for the first time, leaving friends and family behind, coming to a new country, often navigating a non-native language, exposure to cultural differences, etc. Acknowledging the shared experience of international students going through a transition, it is appropriate and insightful to examine their experience through a theoretical framework focused on transition theory. At the crux of transition theory (in addition to defining what a transition is) is the establishment of the four mechanisms of coping: situation, self, support, and strategies (Goodman, Schlossberg, \& Anderson, 2006). Transition theory is applicable to this study, particularly the support mechanism, as it reinforces that support structures (or lack thereof) can impact the academic success of first-year international students in their transition to the university.

A secondary, supporting theoretical framework is Maslow's Hierarchy of Needs (1943). It is particularly useful in this study of the residential experience, as it is one of the most commonly understood and employed theories used by Residence Life professionals. Maslow's Hierarchy of Needs illustrates five sequential levels in which chronological achievement is required for advancement. These levels are Physiological, Safety, Love/Belonging, Esteem, and Self-actualization. Before an individual can progress to the highest level, self-actualization, they must sequentially progress through the lower level. Applying this theory to international students, a student would be unable to achieve academic success until their basic needs (dietary, housing, safety, etc.) are met. Maslow's Hierarchy of Needs challenges administrators to focus on the building blocks of success and to start with the foundation, rather than immediately focusing on the desired outcome.

\section{RESEARCH METHOD}

This experimental study was conducted at a large, four-year public institution located in the northeastern United States. The university has a strong international undergraduate population of approximately 2,600 students, from 115 countries. Of this population, about 550 first-year 
international students reside in on-campus housing, of whom 127 participated in the roommate-pairing program.

The International Roommate Program (IRP) is comprised of two separate programs pairing international and domestic students as roommates in residence halls. This program is designed to provide social support through the intentional pairing of international and domestic roommates. The International Roommate Program \#1 (IRP1) focuses almost exclusively on the pairing of incoming first-year international students with first-year domestic students as roommates in a traditional corridor style building. Program requirements are minimal and attendance at events is optional. To begin the year, the IRP1 had 73 international students and 72 domestic students choose to participate for a total of 145 students. The International Roommate Program \#2 (IRP2) is the flagship program pairing upper-class domestic students with incoming first-year international students as roommates in suite/apartment style residence halls. Students are required to participate in events (including an orientation), receive more communication and guidance from Residence Life staff, and are invited to attend additional optional events/programs. At the start of the year, the IRP2 had 54 international students and 54 domestic students choose to participate for a total of 108 students.

\section{Instrument Design \& Data Collection}

The instrument design was intentionally shaped to address the primary research questions. Due to limited research on this topic, it was not possible to adhere to the best practice of utilizing and modifying an existing survey (Creswell, 2009). As such, surveys were crafted based on the best practices of survey design (Creswell, 2009; Patton, 2008; Patton, 1990; Rossi, Lipsey, \& Freeman, 2003; Weiss, 1998). This quantitative survey was designed to ascertain the participants' perceptions of how living with their current roommate impacted their residential experience, overall satisfaction, and academic success. To ensure effective survey design, the surveys were pilot tested (Creswell, 2008). This pilot test was done with a similar but smaller population of international students from another university to ensure it did not impact the evaluation. Despite the pilot test students' lack of familiarity with the IRP, they provided useful feedback such as the length of time to take the survey, identifying unclear/ambiguous questions, and providing a sample of what the raw data would look like. Pilot testing was especially important in this study, as the survey had to be crafted without using an existing one that has already been validated and deemed as a reliable guide.

This quantitative survey contained approximately 30 questions (measured by a 7-point Likert scale). The survey was administered to the approximate 1,000 international students living in a residence hall at the 
university in April of 2015. The results from 184 participants were used for this study (Table 1). This consisted of 38 participants from the IRP1, 33 from the IRP2, and 113 from the control group of non-program students (NON). Participants from the NON group were identified from the larger dataset collected from all international students residing on campus. The group was limited to international students who either lived in a first-year residence hall or who lived in a mixed class residence hall and were within the age range of a typical first-year student. This sampling yielded response rates of $52 \%, 61 \%$, and $26 \%$, respectively.

\section{Table 1. Sex and Age of sample versus population by Program Type}

\begin{tabular}{|c|c|c|c|c|c|c|}
\hline \multirow[b]{2}{*}{ Category } & \multirow[b]{2}{*}{ Population } & \multicolumn{2}{|l|}{ IRP1 } & \multicolumn{2}{|l|}{ IRP2 } & \multirow{2}{*}{$\begin{array}{l}\text { NON } \\
\text { Sample }\end{array}$} \\
\hline & & Sample & Population & Sample & Population & \\
\hline$\overline{\text { Male }}$ & $66.7 \%$ & $61 \%$ & $34.5 \%$ & $33 \%$ & $53 \%$ & $40 \%$ \\
\hline Female & $43.9 \%$ & $39 \%$ & $63.6 \%$ & $61 \%$ & $47 \%$ & $60 \%$ \\
\hline Age (avg) & 18.7 & 18.6 & 18.8 & 18.7 & 18.8 & 18.9 \\
\hline
\end{tabular}

\section{Statistical Analysis}

Factor analysis was conducted for data reduction as multiple survey questions were asked relative to the same general constructs. Factor analysis is commonly used to reduce the number of items on a survey (Keller, 2015). After running a factor analysis, the analysis of covariance (ANCOVA) allowed for comparison of the three group means (IRP1/IRP2/NON) while statistically controlling for the effects of variables/covariates. ANCOVA levels the field by statistically controlling for the demographics (independent variables) of the IRP1/IRP2/NON international students. The covariates were country, hometown, gender, age, residence hall, roommate status, family attended college, shared bedroom, spent time with American, importance of American roommate, happy living in residence hall, happy going to the University, previously lived in U.S., family lived in U.S., family went to college in U.S., and TOEFL score. Controlling for these covariates increased the likelihood that observed differences were a result of the respective program rather than predisposition of students.

\section{RESULTS AND DISCUSSION}

Consistent with the primary research question, eight themes were developed; Acclimation, Benefitted from having an American Roommate, Development of English Skills, Food, Satisfaction, Enabling Social Relationships, Recommendation based on Residential Experience, and Academic Success. Corresponding survey questions were identified for each theme and clustered together for factor analysis. Within each theme, 
only questions with a correlation of $>.4$ were deemed to be related. Through factor analysis, the respective values of the correlated survey questions were added together to yield a new variable. These eight newly generated variables became the basis for the ANCOVA. Table 2 provides the observed/adjusted means and standard deviations of these eight variables. The results of the ANCOVA found four of the variables, Acclimation, Food, Satisfaction, and Recommendation based on residential experience, to be statistically significant (Table 3).

Table 2: Descriptive Statistics of Variables by Program Type

\begin{tabular}{lcccc}
\hline Variable & $\begin{array}{c}\text { Observed } \\
\text { Mean }\end{array}$ & $\begin{array}{c}\text { Observed } \\
\text { SD }\end{array}$ & $\begin{array}{c}\text { Adjusted } \\
\text { Mean }\end{array}$ & $\begin{array}{c}\text { Adjusted } \\
\text { SD }\end{array}$ \\
\hline IRP1 - Acclimation & 23.76 & 4.21 & 23.72 & 5.21 \\
IRP2 - Acclimation & 26.39 & 4.31 & 27.10 & 5.83 \\
NON - Acclimation & 25.33 & 5.04 & 25.14 & 4.93 \\
IRP1 - Academic Success & 2.90 & .083 & 2.92 & 0.95 \\
IRP2 - Academic Success & 3.20 & .44 & 3.00 & 1.06 \\
NON - Academic Success & 3.05 & .72 & 3.11 & 0.90 \\
IRP1 - Social & 13.97 & 3.28 & 13.39 & 3.41 \\
IRP2 - Social & 13.15 & 2.67 & 14.46 & 3.81 \\
NON - Social & 15.22 & 3.14 & 15.04 & 3.23 \\
IRP1 - Benefit of American & 36.61 & 8.51 & 37.81 & 9.67 \\
IRP2 - Benefit of American & 33.61 & 7.28 & 35.52 & 13.28 \\
NON - Benefit of American & 35.75 & 8.72 & 33.77 & 10.82 \\
IRP1 - English & 24.05 & 4.93 & 23.34 & 5.58 \\
IRP2 - English & 23.06 & 4.42 & 24.91 & 6.25 \\
NON - English & 25.95 & 5.03 & 25.65 & 5.29 \\
IRP1 - Food & 11.66 & 3.87 & 11.73 & 4.67 \\
IRP2 - Food & 14.52 & 3.75 & 14.43 & 5.22 \\
NON - Food & 14.20 & 3.71 & 14.21 & 4.42 \\
IRP1 - Recommendation & 11.03 & 2.14 & 10.93 & 2.11 \\
IRP2 - Recommendation & 11.30 & 1.61 & 11.92 & 2.37 \\
NON - Recommendation & 10.65 & 2.05 & 10.50 & 2.01 \\
IRP1 - Satisfaction & 20.55 & 3.73 & 20.43 & 4.00 \\
IRP2 - Satisfaction & 23.06 & 3.22 & 23.18 & 4.48 \\
NON - Satisfaction & 21.41 & 3.80 & 21.42 & 3.79 \\
\hline
\end{tabular}

While a finding may be statistically significant, that does not mean it is substantial or meaningful to practitioners. To provide context and help better understand the results, seven of the eight studied variables were converted to a 7-point scale to allow for comparison and greater understanding of how international students view their residential experience (Figure 1). The eighth variable, Academic Success, was left on a 4.0 scale to mirror the academic scale on which it is based. Examining the seven variables on a 7-point Likert scale supports the assertion that 
international students (IRP1/IRP2/NON) have a positive residential experience at the University. With the exception of Food for the IRP1, the findings show that international students report being 'neutral' to 'agreeing favorably' that they have a positive experience. This finding reinforces the efforts of Residence Life to create an engaging and welcoming community for all students, regardless of participation in a formal program like the IRP.

\section{Table 3: ANCOVA Results by Program Type}

\begin{tabular}{lccccc}
\hline Variable & SS & Df & MS & F & Sig. \\
\hline Academic Success & .451 & 2 & .226 & .459 & .633 \\
Acclimation & 96.037 & 2 & 48.018 & 3.244 & $.041^{*}$ \\
Benefitted from Amer. & 172.412 & 2 & 86.206 & 1.640 & .199 \\
English Skills & 69.296 & 2 & 34.648 & 2.038 & .134 \\
Food & 97.073 & 2 & 48.536 & 4.086 & $.019^{*}$ \\
Recommendation & 18.901 & 2 & 9.451 & 3.872 & $.023^{*}$ \\
Satisfaction & 63.416 & 2 & 31.708 & 3.629 & $.029^{*}$ \\
Social Relationships & 35.324 & 2 & 17.662 & 2.789 & .064 \\
\hline
\end{tabular}

\begin{tabular}{lcccccc}
\hline Variable & Comparison & $\begin{array}{c}\text { Adj. Mean } \\
\text { Difference }\end{array}$ & s.e. & Sig. & 95\% CI & Cohen’s $d$ \\
\hline Acclimation & IRP1 vs. IRP2 & -3.373 & 1.327 & $.012^{*}$ & $-5.992,-.754$ & -.610 \\
& IRP1 vs. NON & -1.413 & 1.069 & .188 & $-3.524, .699$ & -.279 \\
& IRP2 vs. NON & 1.961 & 1.257 & .121 & $-.522,4.443$ & .370 \\
Food & IRP1 vs. IRP2 & -2.707 & 1.188 & $.024^{*}$ & $-5.054,-.361$ & -.546 \\
& IRP1 vs. NON & -2.481 & .958 & $.010^{*}$ & $-4.372,-.590$ & -.545 \\
& IRP2 vs. NON & .226 & 1.126 & .841 & $-1.997,2.450$ & .047 \\
Satisfaction & IRP1 vs. IRP2 & -2.745 & 1.019 & $.008^{*}$ & $-4.758,-2.607$ & -.646 \\
& IRP1 vs. NON & -.985 & .821 & .232 & $-2.607, .637$ & -.253 \\
& IRP2 vs. NON & 1.760 & .966 & .070 & $-3.668, .147$ & .424 \\
Recommend. & IRP1 vs. IRP2 & -.995 & .539 & .067 & $-2.058, .069$ & -.443 \\
& IRP1 vs. NON & .426 & .434 & .328 & $-.431,1.283$ & .206 \\
& IRP2 vs. NON & 1.421 & .510 & $.006^{*}$ & $.413,2.429$ & .647 \\
\hline
\end{tabular}

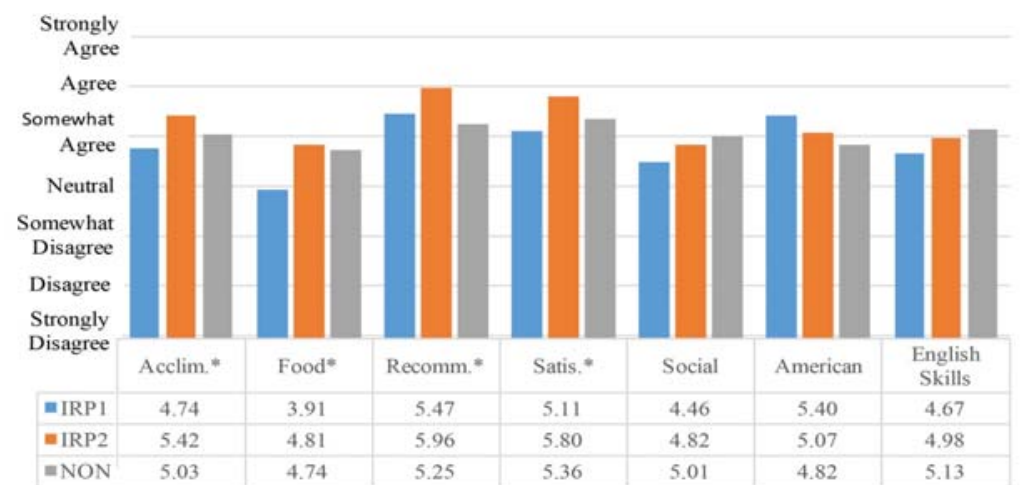

Figure 1. Independent Variables Converted to 7-point Scale (with exception of Academic Success). *Denotes statistical significance $(\mathrm{p}<.05)$. 


\section{Recommendation of the University Based on Residential Experience}

Program type (IRP1/IRP2/NON) was significantly associated with differences in the recommendation of the university based on residential experience $(F=3.872)$. The independent variables 'happiness to be living in a residence hall' $(\mathrm{p}=.000)$ and 'happiness to be attending the University' ( $\mathrm{p}$ $=.000$ ) were significantly associated and statistically controlled for in the ANCOVA. Follow-up tests were conducted to evaluate pairwise differences among the adjusted means. The Bonferroni results showed statistically significant differences between the IRP2 and NON group $(p=.006)$. As expected, the IRP2 had the largest mean (11.92), followed by the IRP1 (M = 10.93), and then NON group $(M=10.50)$.

These findings indicate that students within the IRP2 statistically are more likely to recommend the University to friends/family than their NON counterparts. Furthermore, while it was not statistically significant ( $\mathrm{p}=$ .067), though close, the IRP1 showed a greater likelihood to recommend the University than the NON group. These findings are consistent with the literature and support the assertion that peer-pairing programs are beneficial. Similar to the findings of Quintrell and Westwood (1994), this study found that intentionally pairing international students with domestic peers enhanced their experience, which resulted in their greater likelihood to have a positive view of their experience at the university. This is an especially important finding, as the University enrolls a significant number of international students and it appears that the enhanced experience of IRP2 (and potentially IRP1) participants can increase how likely they are to recommend the University to prospective international students. To this end, developing and growing international roommate-pairing programs could be financially attractive to universities, as they could help in the recruitment and retention of international students.

\section{Acclimation}

Program type (IRP1/IRP2/NON) was significantly associated with differences in self-reported Acclimation $(F=3.244)$. The independent variables 'happiness to live in a residence hall' $(p=.000)$ and 'happiness to attend the University' ( $\mathrm{p}=.013$ ) were significantly associated and statistically controlled for in the ANCOVA. Follow-up tests evaluated pairwise differences among the adjusted means. The Bonferroni results showed statistically significant differences between the IRP1 and IRP2 ( $p=$ .012 ). As expected, the IRP2 had the greatest adjusted mean for acclimation $(M=27.10)$, followed by NON $(M=25.14)$ and then the IRP1 $(M=23.72)$.

These findings indicate that students within the IRP2 (suite-style housing) had greater success acclimating to living on-campus and attending the University than their counterparts in the IRP1 (corridor housing). The benefits of apartment style housing (kitchen facility, privacy, additional 
space, etc.) afforded to the IRP2 may be the primary factor in this increased level of acclimation. Also, students within the IRP2 had an upperclass domestic roommate (IRP1 had first-year roommate) who was familiar with the campus. This familiarity and knowledge may contribute to the greater acclimation of IRP2 international students. Recognizing this, when developing similar international roommate-pairing programs, consideration should be given to the physical environment and the support structure. To this end, this study supports the placements of international students within suite style housing and with upperclass roommates. Doing so can allow students to feel most comfortable in their living accommodations and enable them to readily seek the knowledge of experienced roommate(s) who have successfully navigated the campus.

\section{Food}

Program type (IRP1/IRP2/NON) was significantly associated with differences in self-reported Food Satisfaction $(\mathrm{F}=4.086)$. The independent variable 'happy living in a residence hall' $(\mathrm{p}=.000)$ was significantly associated and statistically controlled for in the ANCOVA. Follow-up tests evaluated pairwise differences among the adjusted means. The Bonferroni results showed a statistically significant difference between IRP1 and IRP2/NON. As expected, the IRP1 had the smallest adjusted mean for Food $(\mathrm{M}=11.73)$, followed by NON $(\mathrm{M}=14.21)$, and then the IRP2 group $(\mathrm{M}=$ 14.43).

These findings indicate that students within the IRP1 (required to eat in dining hall) statistically had less satisfaction with their dietary options compared to their counterparts in both the IRP2 (private kitchens) and NON (some having private kitchens, others eating in the dining hall). This may be the direct result of IRP1 students being placed into corridor style housing, which subsequently requires them to eat the majority of their meals within the dining hall. Students living in apartments (IRP2/NON) may have greater satisfaction as they have kitchens to prepare their own meals. Cooking their own food affords the ability to ensure their dietary needs and taste preferences are met. Consideration should be given to improving international students' satisfaction overall, but particularly within the dining halls. It is notable that of the seven variables studied, that food satisfaction had the lowest mean for each program type compared to the other variables. Furthermore, this lower satisfaction was most notable for the IRP1, as it was the only variable to dip below a positive finding and was situated between somewhat disagree and neutral for satisfaction. These findings are consistent with the literature and previous findings of decreased food satisfaction of international students (Al-Mubarak, 2000; McLachlan \& Justice, 2009; Terkla et al., 2005). Residence Life can explore ways to 
improve the dining experience or determine if there is a dining facility elsewhere on campus that better meets the needs of international students.

\section{Satisfaction}

Program type (IRP1/IRP2/NON) was significantly associated with differences in self-reported Satisfaction $(\mathrm{F}=3.629)$. The independent variables 'happiness to live in a residence hall' $(p=.000)$ and 'happiness to attend the University' $(\mathrm{p}=.004)$ were significantly associated and statistically controlled for in the ANCOVA. Follow-up tests were conducted to evaluate pairwise differences among the adjusted means. The Bonferroni results showed statistically significant differences between the IRP1 and IRP2 ( $\mathrm{p}=.008)$. As expected, the IRP1 had the smallest adjusted mean for Satisfaction $(M=20.43)$, followed by the NON $(M=21.42)$ and then the IRP2 group $(M=23.18)$.

The findings indicate that students within the IRP2 (suite style housing) statistically had greater satisfaction with their overall experience compared to their counterparts in the IRP1 (corridor housing). This greater level of satisfaction may likely be a product of the benefits afforded from living in apartment style housing (kitchen, nicer facility, more space, privacy, etc.). It also is likely directly related to the IRP2 students increased acclimation and food satisfaction. This finding supports developing roommate-pairing programs that utilize suite style housing.

\section{Academic Success}

Program type (IRP1/IRP2/NON) was not significantly associated with differences in self-reported Academic Success ( $\mathrm{F}=.459)$. Interestingly, there was not an observed association of the independent variables with Academic Success. In particular, it is surprising that TOEFL score did not have a correlation with Academic Success. This warrants further exploration in future studies, as it would be a logical assumption that students with a lower TOEFL score would be more likely to struggle academically at a U.S. institution.

These findings for Academic Success indicate that differences between IRP1/IRP2/NON was minimal and not statistically significant ( $\mathrm{p}=$ .633). It is worth noting that the self-reported GPA for the Fall Semester by the IRP1/IRP2/NON participants was respectable (2.92. 3.0, 3.11, respectively), especially for first-year students learning to navigate the college campus and learning to be a student. While this study only explored Fall GPA, it would be interesting to see the impact of the IRP on Spring GPA and subsequent years. Furthermore, examining other form of Academic Success such as retention and persistence could show long term benefits of the IRP. 
As administrators develop and strengthen international roommatepairing programs, Academic Success ought to be a primary goal or objective of their program. This could include building in resources like tutoring, English language development, study facilities, targeted academic advising, etc. In these difficult financial times at universities, it can be tough to secure (additional) funding to support programs and initiatives. If Residence Life can demonstrate enhanced Academic Success for international students, this can serve to better market the program and establish the need for university support.

\section{Benefitted from having an American Roommate}

Program type (IRP1/IRP2/NON) was not significantly associated with differences in perceived benefit of having an American roommate $(\mathrm{F}=1.640)$. The independent variables 'happiness to live in a residence hall' $(\mathrm{p}=.014)$, 'happiness to attend the University' $(\mathrm{p}=.05)$, and 'previously lived in U.S.' ( $\mathrm{p}=.013$ ) were significantly associated and statistically controlled for in the ANCOVA. The IRP1 had the greatest adjusted mean for having benefited by having an American roommate $(\mathrm{M}=37.81)$, followed by the IRP2 $(\mathrm{M}=35.52)$ and then the NON group $(\mathrm{M}=33.77)$.

These findings indicate that students within the IRP1/IRP2/NON found equal benefit from having an American roommate regardless of program involvement. This finding is consistent with the literature and to be expected as the experience of interacting with Americans is one of the greatest priorities for international students. While not statistically significant, it is notable that the means were higher for the IRP compared to the NON participants. These higher means for the IRP may be attributed to the desire of participants to live with an American roommate, thus they selfselected into the International Roommate-Pairing Program (compared to the NON participants who were placed with an American roommate by chance).

The factor of 'previously lived in the U.S.' is particularly interesting, as it is reasonable to conclude these students may not benefit from having an American roommate as much as students without that experience. Future studies ought to further examine students with previous experience in the U.S, as Residence Life could explore ways to modify the program to enhance their experience. This may include students being partnered in some way with other international students (not previously exposed to the U.S.), creating a component of the program specifically for them, and/or modifying future program requirements (i.e. required orientation).

\section{Enabling Social Relationships}

Program type (IRP1/IRP2/NON) was not significantly associated with differences in self-reported Social Relationships $(\mathrm{F}=2.789)$. The 
independent variables 'home country' $(\mathrm{p}=.002)$, 'roommate status' $(\mathrm{p}=$ .005), 'previously sharing a bedroom' $(\mathrm{p}=.041)$, 'time spent with an American' ( $p=.012)$, 'happiness to living in a residence hall' $(p=.013)$, 'family having lived in the U.S.' $(p=.038)$, and 'TOEFL score' $(p=.001)$ were significantly associated and statistically controlled for in the ANCOVA. The NON had the greatest adjusted mean for enabling social relationships $(M=15.04)$, followed by the IRP2 $(M=14.46)$ and then the IRP1 group $(\mathrm{M}=13.39)$.

These findings indicate that the difference between program type was minimal and not statistically significant. The social programming aspect of the IRP was intended to create opportunities for relationship-building; however, this was not found, and, in fact, the NON group reported greatest social opportunities. A possible explanation for these findings is that residence halls are a social environment by design. There is a large number of students living in close proximity who commonly participate in social programming hosted by Residence Life intended to build a sense of community and relationships amongst students. Subsequently, students may feel included and have established opportunities for social engagement and relationship building even when they are not part of an intentional program aimed at facilitating social interactions.

\section{Development of English Skills}

Program type (IRP1/IRP2/NON) was not significantly associated with differences in self-reported English Skills $(\mathrm{F}=2.038)$. The independent variables 'home country' $(p=.002)$, 'roommate status' $(p=.020)$, 'time spent with an American' ( $\mathrm{p}=.025)$, 'happiness to live in a residence hall' ( $\mathrm{p}$ $=.031)$, and 'TOEFL score' $(\mathrm{p}=.002)$ were significantly associated with English skills and statistically controlled for in the ANCOVA. The NON group had the greatest adjusted mean for development of English skills ( $\mathrm{M}=$ 25.65), followed by the IRP2 $(M=24.91)$ and then the IRP1 group $(M=$ 23.34).

These findings indicate that all international students developed English skills equally regardless of program involvement. It may be that all international students are sufficiently exposed to the English language in and out of the classroom thereby mitigating differences between the IRP1/IRP2/NON. Similar to the findings of Enabling Social Relationships, the residence halls provide a social environment that fosters interaction between students. Perhaps this environment (and the overall experience at the university) provides ample opportunities for international students to develop English skills. 


\section{CONCLUSION}

The following key findings support the conclusion that participation does indeed have a positive impact and that it is influenced by the physical environment and structured support:

1. Students participating in the IRP who lived in suite style housing and had upperclass roommates (IRP2) were more likely to recommend the University based on their residential experience than students who did not participate in the program (NON).

2. It is notable (though not statistically significant) that the IRP2 (suitestyle housing \& upperclass roommate) had greater overall satisfaction, acclimation, food satisfaction, and perceived benefit from having an American roommate than NON participants.

3. In comparing the two implemented versions of the International Roommate-Pairing Program, participants in the IRP2 (suite-style housing \& upperclass roommate) had greater overall satisfaction, acclimation, and food satisfaction than those in the IRP1 (corridor housing \& first-year roommate).

4. International students who had the majority of their meals in the dining hall had decreased food satisfaction. IRP students who were required to eat in the dining hall (IRP1) had lower food satisfaction than both the IRP2 (private kitchens) and NON (some having private kitchens, others eating in the dining hall).

Based on these findings, the version of the international roommatepairing program that takes places in suite-style housing with upper class roommates (IRP2) is the most promising. The IRP2 affords international students the dual benefit of a residential environment that best accommodates their needs and provides additional layers of support through an experienced, upper class roommate. This suite-style housing provides an environment where international students can relax and feel they are at home (Tas, 2013). This inclusion of a private bathroom and less restriction in their living space better accommodates their needs. This residential experience is complimented and further enhanced by being paired with an American peer. It has long been noted that peers are crucial in student development (Astin, 1975) and international students are no exception. This pairing provides international students with a support structure and affords them the desired experience of developing relationships with American students. This social support enhances their experience, diminishes their likelihood of feeling isolated, and provides an additional layer of support.

Subsequently, as Residence Life professionals develop new programs and strengthen existing ones, strong consideration should be given to addressing the physical environment and layers of peer support. To help inform their practice, the theoretical framework of Maslow (1943) for 
physical environment and Schlossberg et al. (1995) for support structures can be utilized. While this study identified ways to improve the residential experience for international students, it is notable and impressive that reported satisfaction levels of all international students (regardless of IRP participation) were positive. By and large, all of these students reported between neutral and agreeing favorably for each variable. These positive results reinforce Residence Life's effort to create a residential community that is inclusive and supportive.

\section{CONSIDERATION FOR FUTURE STUDIES}

Ideally, future studies would compare programs with similar environments, thus making it easier to draw conclusions, determine causality, and generalize the study. The study of the IRP1/IRP2 proved to be challenging as there were different living environments (corridor vs. suite style), dietary accommodations (dining hall vs. private kitchen), roommate status (upperclass vs. freshmen), and program requirements (optional vs. required components). It would be particularly interesting and beneficial to replicate the IRP1/IRP2 program but create a version of each in corridor and suitestyle housing. Doing so would eliminate differences in living environment (including dietary) and better facilitate program evaluation with the nonparticipants. To this end, comparing similar environments would more effectively allow an "apples-to-apples” comparison.

Efforts must also be made to increase response rate of participants. While email surveys are the most convenient and cost effective method of distribution, they may become an unusable medium due to the high volume of emails college students receive from administrators/faculty. Additionally, students often receive surveys seeking feedback, as program evaluation and assessment has become an expectation from many departments/programs. This "flooding" of their inbox likely influenced the low response rate in this study. This is perplexing for the future state of research within Higher Education, as it threatens the number of quantitative studies that can be conducted.

\section{REFERENCES}

Abe, J., Talbot, D. M., \& Geelhoed, R. (1998). Effects of a peer program on international student adjustment. Journal of College Student Development, 39(6), 539-547.

Al-Mubarak, A. H. (2000). Adjustment problems, coping methods, and choice of helpers of international students attending a large Pennsylvania university. Dissertation Abstracts International, 61(1-A).

Andrade, M. S. (2005). International students and the first year of college. Journal of The First-Year Experience \& Students in Transition, 17(1), 101-129. 
Andrade, M. S. (2006). International students in English-speaking universities adjustment factors. Journal of Research in International Education, 5(2), 131-154.

Antonio, L.M., \& Ofori-Dwumfuo, C. (2015). Understanding Communication Dynamics Among International and Domestic Students: A Case Study of a Global Living-Learning Community. Journal of College \& University Student Housing, 42(1), 128-143.

Astin, A. W. (1975). Preventing students from dropping out. San Francisco: Jossey-Bass.

Aw, F. (2012). The international student question: 45 years later. Journal of College Admission, 214, 10-11.

Becker, R., \& Kolster, R. (2012). International student recruitment: policies and developments in selected countries. The Hague,Netherlands: Nuffic.

Bevis, T. B. (2002). 'At a glance: International students in the United States'. International Educator, 11(3), 12-17.

Chong, J. K., \& Razek, N. A. (2014). Feeling welcome with no "buts": Chinese student engagement in residence life. Academy of Educational Leadership Journal, 18(3), 137-149.

Creswell, J. W. (2009). Research design: Qualitative, quantitative and mixed methods approaches (3rd ed.). Thousand Oaks, CA: Sage.

Dodge, S. (1990). Culture shock and alienation remain problems for many foreign students on U.S. campuses. Chronicle of Higher Education. Retrieved from: US/69974/

Furnham, A. F., \& Bochner, S. (1982). Social difficulty in a foreign culture: An empirical analysis of culture shock. In S. Bochner (Ed.), Cultures in contact: Studies in cross-cultural interactions (pp. 161-198). Oxford: Pergamon.

Geelhoed, R. J., Abe, J., \& Talbot, D. M. (2003). A qualitative investigation of US students' experiences in an international peer program. Journal of College Student Development, 44(1), 5-17.

Gomez, G, Urzua, A., \& Glass, C. R. (2014). International student adjustment to college: Social networks, acculturation, and leisure. Journal of Park and Recreation Administration, 32(1), 7-25.

Goodman, J., Schlossberg, N., \& Anderson, M. (2006). Counseling adults in transition: Linking practice with theory ( $3^{\text {rd }}$ ed.). New York: Springer.

Grebennikov, L., \& Skaines, I. (2007). Comparative analysis of student surveys on international student experience in higher education. Journal of Institutional Research, 13(1), 97-116.

Hechanova-Alampay, R., Beehr, T. A., Christiansen, N. D., \& Van Horn, R. K. (2002). Adjustment and strain among domestic and international student sojourners: A longitudinal study. School Psychology International, 23(4), 458-474.

Hegarty, N. (2014). Where we are now-The presence and importanceof international students to universities in the United States. Journal of International Students, 4(3), 223-235.

Hendrickson, B., Rosen, D., \& Aune, R. (2011). An analysis of friendship networks, social connectedness, homesickness, and satisfaction levels of international 
students. International Journal of Intercultural Relations, 35, 281-295.

IIE (2015). Open Doors 2015: Report on International Student Exchange. Institute of International Education. Retrieved from http://www.iie.org/Researchand-Publications/Open-Doors

Keller, D. K. (2015). The Tao of Statistics: A Path to Understanding (with no math). Thousand Oaks, CA: Sage.

Kovtun, O. (2011). International student adaptation to a US college: A mixed methods exploration of the impact of a specialized first-year course at a large Midwestern institution. Journal of Student Affairs Research and Practice, 48(3), 349-366.

Kwai, C. K. (2009). Model of international student persistence: Factors influencing retention of international undergraduate students at two public statewide four-year university systems. Unpublished doctoral dissertation, University of Minnesota.

Lee, J. J., \& Rice, C. (2007). Welcome to America? International student perceptions of discrimination. Higher Education, 53(3), 381-409.

Mamiseishvili, K. (2012). International student persistence in US postsecondary institutions. Higher Education, 64(1), 1-17.

Maslow, A. H. (1943). A theory of human motivation. Psychological Review, 50(4), 370-396.

McFaul, S. (2016). International Students' Social Network: Network Mapping to Gage Friendship Formation and Student Engagement on Campus. Journal of International Students, 6(1), 1-13.

McLachlan, D. A., \& Justice, J. (2009). A grounded theory of international student well-being. Journal of Theory Construction \& Testing, 13(1), 27-32.

Menzies, J. L., Baron, R., \& Zutshi, A. (2015). Transitional experiences of international postgraduate students utilising a peer mentor programme. Educational Research, 57(4), 403-419.

Patton, M. Q. (1990). Qualitative evaluation and research methods. Newbury Park: Sage.

Patton, M. Q. (2008). Utilization-focused evaluation (4th ed.). Thousand Oaks, CA: Sage.

Quintrell, N., \& Westwood, M. (1994). The influence of a peer-pairing program on international students' first year experience and use of student services. Higher Education Research and Development, 13(1), 49-57.

Ragavan, S. K. (2014). Peer mentoring for international students in a UK law school: lessons from a pilot case study. Innovations in Education and Teaching International, 51(3), 292-302.

Rajapaksa, S., \& Dundes, L. (2002). It's a long way home: International student adjustment to living in the United States. Journal of College Student Retention: Research, Theory and Practice, 4(1), 15-28.

Ramsay, S., Jones, E., \& Barker, M. (2007). Relationship between adjustment and support types: Young and mature-aged local and international first year university students. Higher education, 54(2), 247-265.

Rossi, P. H., Lipsey, M. W., \& Freeman, H. E. (2003). Evaluation: A systematic approach (7th ed.). Thousand Oaks, CA: Sage. 
Saidla, D. D., \& Grant, S. (1993). Roommate understanding and rapport between international and American roommates. Journal of College Student Development, 35(5), 335-340.

Saidla, D. D., \& Parodi, R. (1991). International and American roommate relationships. College Student Affairs Journal, 10(3), 54-69.

Sawir, E., Marginson, S., Deumert, A., Nyland, C., \& Ramia, G. (2008). Loneliness and international students: An Australian study. Journal of Studies in International Education, 12(2), 148-180.

Schlossberg, N, Waters, E., \& Goodman, J. (1995). Counseling adults in transition: Linking practice with theory ( $2^{\text {nd }}$ ed.). New York: Springer.

Tas, M. (2013). Best practices in hosting international students in the US. CrossCultural Communication, 9(2), 14-17.

Terkla, D. G., Roscoe, H. S., \& Etish-Andrews, J. (2005). Voices from around the World: International Undergraduate Student Experiences. 45th Annual Association for Institutional Research Forum. Unpublished paper.

Tompson, H. B. \& Tompson, G. H (1996). Confronting diversity issues in the classroom with strategies to improve satisfaction and retention of international students. Journal of Education for Business, 72(1), 53-57.

Weiss, C. (1998). Evaluation ( $2^{\text {nd }}$ ed.). Upper Saddle River, NJ: Prentice Hall.

Wilhelm, I. (2011). U.S. colleges seek greater diversity in foreign-student enrollment. Chronicle of Higher Education. Retrieved from: http://www.chronicle.com/article/US-Colleges-Seek-Greater/129098/

Woodrow, L. (2006). Academic success of international postgraduate education students and the role of English proficiency. University of Sydney papers in TESOL, 1(1), 51-70.

STEVEN TOLMAN, EdD, is an Assistant Professor of Educational Leadership (Higher Education) at Georgia Southern University. His research interests include management and leadership practices within higher education and the residential experience of college students at U.S. institutions. Email: StevenTolman@gmail.com. 